ScIDice

\section{Prevalence Of Patterns of Gothic Arch Tracings in BPS Dentures Obtained by Post Graduates in Saveetha Dental College - A Retrospective Study}

Research Article

Madhura Deshmukh ${ }^{1}$, Nabeel Ahmed ${ }^{2 *}$, Saloni Kachhara ${ }^{3}$

${ }^{1}$ Post Graduate Student, Department of Prosthodontics and Implantology, Saveetha Dental College And Hospitals, Saveetha Institute Of Medical, And Technical Sciences, Saveetha University, Chennai-600077, Tamilnadu, India.

${ }^{2}$ Senior Lecturer, Department of Prosthodontics and Implantology, Saveetha Dental College And Hospitals, Saveetha Institute Of Medical And Technical Sciences, Saveetha University, Chennai-600077, Tamilnadu, India.

${ }^{3}$ Postgraduate student in Prosthodontics, Saveetha Dental College And Hospitals, Saveetha Institute Of Medical And Technical Sciences, Saveetha University, Chennai-600077, Tamilnadu, India.

\title{
Abstract
}

For patients seeking complete denture treatment, it is often difficult to manipulate the mandible into the centric relation position due to the habitual closure induced by ill fitting dentures or may be trismus. Although, there has always been controversy existing in the field of inter occlusal records. Intraoral gothic arch tracers provide the advantage of capturing the vertical dimension of occlusion and centric relation in an easy-to-use technique for practitioners. Intraoral gothic arch tracing is a preferred method of obtaining consistent positions of mandibular movements in centric and eccentric positions. The purpose of this study was to determine the prevalence of patterns of gothic arch tracings in bps denture made in saveetha dental college. A total of 72 sheets were analysed and reviewed. Experimental groups consisted of individuals who agreed for bps complete denture treatment. A photographic image of the patterns of gothic arch tracings and prevalence of patterns and its association with age group and gender was statistically analyzed. The prevalence of Typical pattern in $68.06 \%$, followed by double arrow point pattern in $15.28 \%$, atypical and miniature pattern equally in $6.94 \%$ and least asymmetrical pattern in $2.78 \%$ was found in the given population.For all age groups, Typical pattern(Green) was the most prevalent. Chi Square test [(Pearson's Chi-square value: 10.07, df : 8, p-value: $0.260(\mathrm{p}>0.005)]$ was done showing no association between patterns of gothic arch tracing and age. In both Males and Females, Typical pattern (blue) was most prevalent. Asymmetrical is least prevalent. Chi Square test [(Pearson's Chi-square value: 5.224, df : 4, $p$-value: 0.265 ( $p>0.005)]$ was done showing no association of patterns of gothic arch tracing and gender.

Keywords: Centric Relation; Complete Denture; Gothic Arch Tracing; Patterns.

\section{Introduction}

In order to get optimum esthetics, function and phonetics in complete denture fabrication, it's necessary to accurately record the maxillo-mandibular determinants of occlusion. It requires clinical skills to establish an accurate, repeatable and verifiable measurement of the vertical dimension of occlusion and centric relation [1].

The Gothic arch (arrow point) tracing was first introduced to the dental profession by Gysi in 1910 for recording centric jaw relation. The Gothic arch tracer has been acknowledged as one of the most reliable and accurate patient-guided methods for obtaining the centric relation, which is especially suitable for the patients who could not obtain the correct maxillo-mandibular record relationship by operator-guided recording methods [2].

It's quite a challenging thing for all dental professionals, often more the prosthodontist to achieve a stable denture especially the mandibular denture.Stability of mandibular complete dentures are often improved by reducing the transverse forces on the denture base through inclusion of linear (non interceptive) occlusion, selecting an occlusal plane that limits the horizontal vectors of force at occlusal contact and utilization of a central bearing intraoral Gothic arch tracing to record jaw relations [3].

\section{*Corresponding Author:}

Dr. Nabeel Ahmed,

Senior Lecturer, Department of Prosthodontics and Implantology, Saveetha Dental College and Hospitals, Saveetha Institute of Medical and Technical Sciences, Saveetha University,

Chennai 77, India.

Tel: 7204914145

E-mail: nabeel.5610@gmail.com

Received: October 28, 2019

Accepted: November 24, 2019

Published: November 28, 2019

Citation: Madhura Deshmukh, Nabeel Ahmed, Saloni Kachhara. Prevalence Of Patterns of Gothic Arch Tracings in BPS Dentures Obtained by Post Graduates in Saveetha Dental College - A Retrospective Study. Int J Dentistry Oral Sci. 2019;S5:02:002:6-10. doi: http:/ /dx.doi.org/10.19070/2377-8075-SI02-05002

Copyright: Nabeel Ahmed 2019 . This is an open-access article distributed under the terms of the Creative Commons Attribution License, which permits unrestricted use, distribution and reproduction in any medium, provided the original author and source are credited. 
In 1927, Phillips et al [4], stated that the apex of gothic arch tracing indicates correct centric position. A study conducted by Kapur et al [5], concluded that the intraoral tracing procedure is more consistent than extra oral tracing/wax registration for recording centric relation in complete denture prosthesis

In the study by Myers et al [6], it was observed that there is no evidence in support of the context that a dentist assisted jaw relation is more reproducible than the jaw relation indicated by Gothic arch apex.

Prosthodontists all over the world emphasize on being able to provide their complete denture patients with prosthesis that has a natural look, have an aesthetically pleasing profile and provide optimum functionality. Although to obtain such denture there should be balanced occlusion in it. This can be achieved by determining the vertical dimension in occlusion in harmony with musculature of the patient and recording a repeatable and verifiable centric relation.

Previously numerous clinical trials [7-9], systematic reviews [1012], reviews [13-15], in vitro studies [16, 17], case reports [17-19] and surveys $[20,21]$ have been conducted in Saveetha dental college over the past few years. Now, we are carrying out many such epidemiological researches with our huge university database. The aim of this study was to determine the prevalence of patterns of gothic arch tracings in BPS ${ }^{\mathrm{TM}}$ denture made in saveetha dental college.

\section{Materials and Methods}

This retrospective study was done in a university setup in Chennai, India where it has the advantages of a controlled environment. Ethical clearance was given from the Institutional Human Ethical Committee of Saveetha Dental College and Hospital, SIMATS, Chennai with the following ethical approval number SDC/SIHEC/2020/DIASDATA/0618-0319.

A total of 72 sheets were assessed and reviewed and the data was tabulated in MS Excel ${ }^{\mathrm{TM}}$ (Microsoft Office, USA). Data collection was done from a university database, it followed the path as Prosthodontics, BPS denture, Final Impression and then Gothic arch tracing, dated from 16th August 2019 to 30th March 2019. Statistical analysis was done using SPSS Statistics Software for windows, version 20.0. Pearson correlation was done to determine that is there any statistical significant difference between patterns of gothic arch tracings and age \& gender.

Experimental group consisted of patients seeking prosthodontic treatment as BPS complete denture This denture system uses the Gnathometer M as the intraoral tracer. Analysis of the patterns of gothic arch tracing was done retrospectively. A photographic image of the pattern of tracing was taken up and assessed. Only postgraduate students with various clinical experience were included in this study.

Output variables assessed were the prevalence of patterns of gothic arch tracing association with age groups and gender. The management of incomplete/censored data was represented as missing data/using formulas to calculate linear regression.

Cross verification of data was checked and evaluated by reviewer and re-discussed.Internal and external validity of sample selected was justified by homogeneity of sample as all samples agreed for pursuing BPS complete denture and variables were performed by postgraduates. Chi square test, Crosstabs were used for the descriptive statistical correlation and descriptive bar charts were obtained.

\section{Results and Discussion}

Retrospective analysis of gothic arch tracings obtained when recording of centric relation during fabrication of bps denture for the patients was assessed. A total of 72 sheets were analysed and data for which was extracted from the university database.

The patterns of gothic arch tracing were categorized under five headings as shown in (Figure 1). The photographic image described the category of the pattern of gothic arch tracing and then its association with age group was statistically analyzed. (Table 1) depicts the pattern of tracings obtained in the various age groups.It was observed that the typical arrow point pattern followed by the double arrow point pattern was more prevalent in all the age groups.

Intraoral gothic arch tracers are advantageous over their extraoral counterparts also because they can be used with greater simplicity. Use of intraoral gothic arch tracing device is simple, efficient, relatively consistent and it determines vertical dimension of occlusion and records repeatable retruded centric relation which helps in fabrication of complete denture and is also used in extremely resorbed ridges (Geneva Dental, Beverly Hills, CA).

Table 1. Frequency distribution of intraoral gothic arch tracing according to patterns shows distribution of typical pattern in $68.1 \%$ followed by double arrow point in $15.3 \%$, atypical and miniature pattern equally in $6.9 \%$ and least asymmetrical in $2.8 \%$.

\begin{tabular}{|c|c|c|}
\hline $\begin{array}{c}\text { PATTERNS OF GOTHIC } \\
\text { ARCH TRACING }\end{array}$ & & \\
\cline { 2 - 3 } & Frequency & Percent \\
\hline ATYPICAL & 5 & 6.9 \\
\hline TYPICAL & 49 & 68.1 \\
\hline ASYMMETRICAL & 2 & 2.8 \\
\hline DOUBLE ARROW POINT & 11 & 15.3 \\
\hline MINIATURE & 5 & 6.9 \\
\hline Total & 72 & 100 \\
\hline
\end{tabular}


Figure 1. Commonly seen patterns of gothic arch tracing observed during recording of centric relations such as Typical, Atypical, Asymmetrical, Double Arrow point and Miniature.

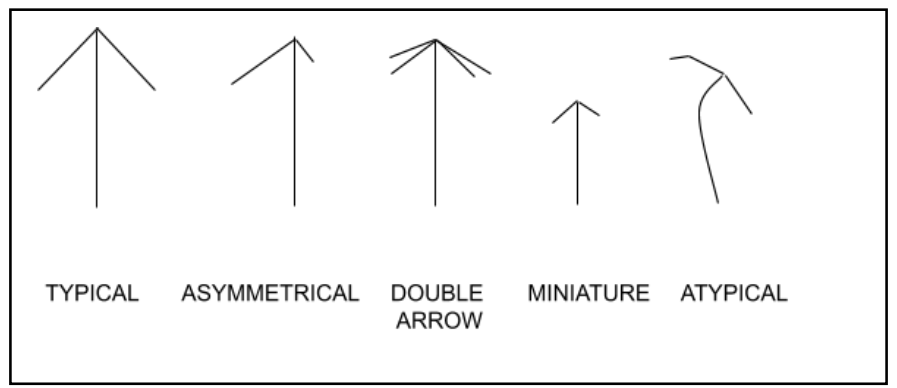

Figure 2. Bar graph depicts various patterns of intra oral gothic arch tracing during recording of centric relation in complete denture patients. $\mathrm{X}$-axis represents patterns of tracing obtained during recording centric relation position and $\mathrm{Y}$ axis represents number of patients. The graph shows prevalence of Typical pattern in $68.06 \%$, followed by double arrow point pattern in $15.28 \%$, atypical and miniature pattern equally in $6.94 \%$ and least asymmetrical pattern in $2.78 \%$.

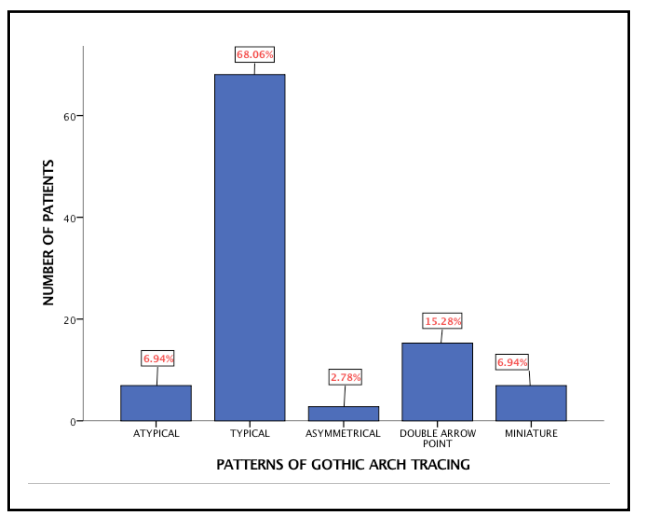

Figure 3. Bar graph depicting various patterns of gothic arch tracing in complete denture patients. X-axis represents age groups, $\mathrm{Y}$ axis represents percentage of prevalent patterns of gothic arch tracing. For all age groups, Typical pattern(Green) was the most prevalent. Chi Square test [(Pearson's Chi-square value: 10.07, df : 8, p-value: 0.260 (p>0.005)] was done showing no association between patterns of gothic arch tracing and age making them statistically insignificant.

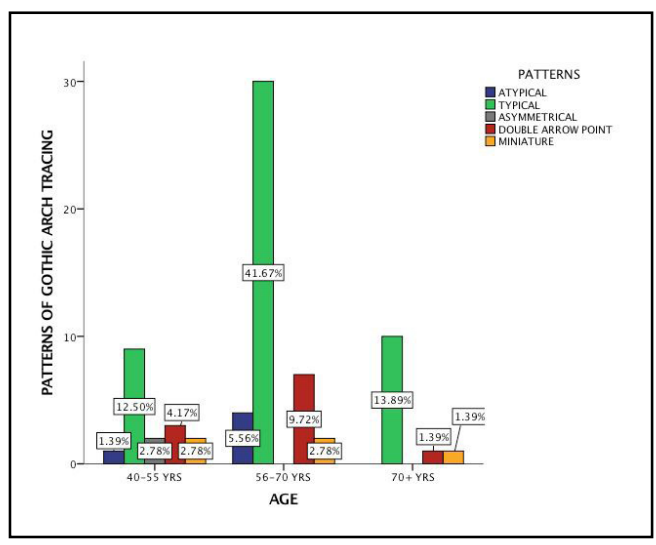

Linear occlusion has been reported to significantly reduce transverse force vectors and to provide a consistent vertical seating force in both centric and eccentric mandibular movement, thus improving the stability [22, 23], Winkler S,1996, [24-26]. Mandibular denture base stability is reported to be increased through the linear occlusion (Gronas et al, 1974).

The use of intra oral gothic arch tracing devices is a simple, efficient and relatively consistent technique to determine both vertical dimension in occlusion and record a repeatable jaw relationship when fabricating complete dentures [27]. In 1999, Fenlon
[28], has demonstrated a positive correlation between complete denture usage and the accuracy of the maxillomandibular relationship record(MMRR).

An inappropriate complete denture would lead to mandibular protrusion and deviation [29]. The Biofunctional Prosthetic System (BPS, Ivoclar Vivadent AG, Liechtenstein) for complete denture uses the 'Gnathometer M', which consists of wax rims and the Gothic arch tracer mounted to the nal impression. This can pro- vide better retention and stability, and is also easier to operate compared with the traditional Gothic arch tracer [30]. 
Figure 4. Bar graph depicting various patterns of gothic arch tracing in complete denture patients. X-axis represents gender, $\mathrm{Y}$ axis represents prevalent patterns of gothic arch tracing. In both Males and Females, Typical pattern (blue) was most prevalent. Asymmetrical is least prevalent. Chi Square test [(Pearson's Chi-square value: 5.224, df : 4, p-value: 0.265 $(p>0.005)]$ was done showing no association of patterns of gothic arch tracing and gender making them statistically insignificant.

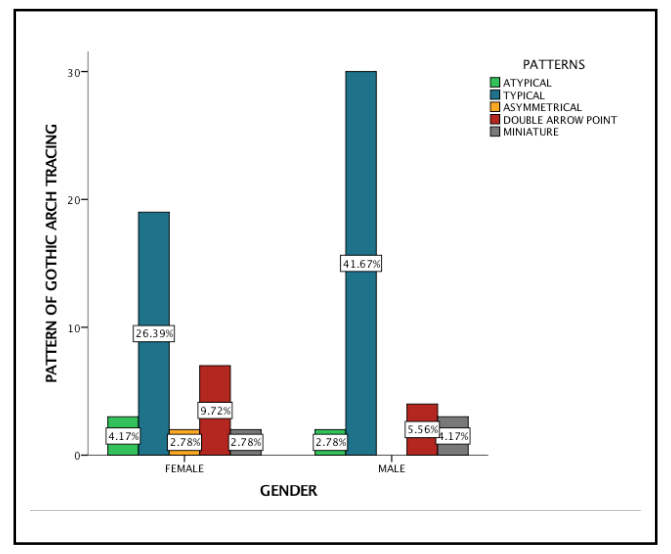

Evidence provided previously in studies by Posselt et al in 1952, Boucher et al., in 1961 and Aprile et al., in 1947 [31-33], suggests that the character of the Gothic arch or arrow-point (needlepoint) tracing is remarkably similar to that of the vertical range of the hinge opening movement.

In this study, retrospective analysis of prevalence of patterns of gothic arch tracings in patients obtained when recording of centric relation was done during fabrication of bps denture was assessed. Also, the prevalence of association of patterns of gothic arch tracings with age groups and gender was analysed. It was found that the typical arrow point pattern followed by the double arrow point pattern was more prevalent in all the age groups. Also, it was observed that the typical arrow point pattern followed by the double arrow point pattern was more prevalent in both males and females.

\section{Limitations}

Since the study had inclusion of dental students, the possibility of standard operating protocols set by the university and the heterogeneity of faculty guiding the procedure may have influenced the outcome.

\section{Conclusion}

Within its limitations, this study concludes that the majority of patterns obtained during intraoral gothic arch tracing were of typical type followed by double arrow point in association to various age groups. Typical pattern of gothic arch tracing was also prevalent in both men and women, followed by the double arrow point pattern. The overall least pattern observed during intraoral gothic arch tracing was asymmetrical.

\section{References}

[1]. Rubel B, Hill EE. Intraoral gothic arch tracing. New York State Dental Journal. 2011 Aug 1;77(5):40.

[2]. Wei X, Luo XP. Correction sof horizontal mandibular position in an edentulous patient accustomed to mandibular protrusion and deviation using the Gothic arch tracer. INTERNATIONAL JOURNAL OF CLINICAL AND EXPERIMENTAL MEDICINE. 2017 Jan 1;10(11):15526-31.

[3]. Williamson RA, Williamson AE, Bowley J, Toothaker R. Maximizing man- dibular prosthesis stability utilizing linear occlusion, occlusal plane selection, and centric recording. J Prosthodont. 2004 Mar;13(1):55-61.Pubmed PMID: 15032898

[4]. Phillips GP. Fundamentals in the reproduction of mandibular movements in edentulous mouths. The Journal of the American Dental Association (1922). 1927 Mar 1;14(3):409-15.

[5]. Kapur KK, Yurkstas AA. An evaluation of centric relation records obtained by various techniques. J Prosthet Dent. 1957 Nov 1;7(6):770-86.

[6]. Myers M, Dziejma R, Goldberg J, Ross R, Sharry J. Relation of Gothic arch apex to dentist-assisted centric relation. J Prosthet Dent. 1980 Jul;44(1):7881. Pubmed PMID: 6929927.

[7]. Jyothi S, Robin PK, Ganapathy D. Periodontal health status of three different groups wearing temporary partial denture. Research J. Pharm. and Tech. 2017;10(12):4339-42.

[8]. Duraisamy R, Krishnan CS, Ramasubramanian H, Sampathkumar J, Mariappan S, Navarasampatti Sivaprakasam A. Compatibility of Nonoriginal Abutments With Implants: Evaluation of Microgap at the Implant-Abutment Interface, With Original and Nonoriginal Abutments. Implant Dent. 2019 Jun;28(3):289-295. Pubmed PMID: 31124826.

[9]. Ganapathy D, Sathyamoorthy A, Ranganathan H, Murthykumar K. Effect of Resin Bonded Luting Agents Influencing Marginal Discrepancy in All Ceramic Complete Veneer Crowns. J Clin Diagn Res. 2016 Dec;10(12):ZC67ZC70.Pubmed PMID: 28209008.

[10]. Jain AR, Nallaswamy D, Ariga P, Ganapathy DM. Determination of correlation of width of maxillary anterior teeth using extraoral and intraoral factors in Indian population: A systematic review. World J Dent. 2018 Jan;9:68-75.

[11]. Kannan A. Effect of Coated Surfaces influencing Screw Loosening in Implants: A Systematic Review and Meta-analysis. WJOUD. 2017 Nov;8(6):496-502.

[12]. Kannan A, Venugopalan S. A systematic review on the effect of use of impregnated retraction cords on gingiva. RJPT. 2018;11(5):2121-6.

[13]. Selvan SR, Ganapathy D. Efficacy of fifth generation cephalosporins against methicillin-resistant Staphylococcus aureus-A review. RJPT. 2016;9(10):1815-8.

[14]. Subasree S, Murthykumar K, Dhanraj. Effect of Aloe Vera in Oral Health. Research Journal of Pharmacy and Technology. 2016;9: 609.

[15]. Vijayalakshmi B, Ganapathy D. Medical management of cellulitis . Research Journal of Pharmacy and Technology. 2016;9:2067.

[16]. Ranganathan H, Ganapathy DM, Jain AR. Cervical and Incisal Marginal Discrepancy in Ceramic Laminate Veneering Materials: A SEM Analysis. Contemp Clin Dent. 2017 Apr-Jun;8(2):272-278.

[17]. Ajay R, Suma K, Ali SA, Kumar Sivakumar JS, Rakshagan V, Devaki V, Divya K, et al. Effect of Surface Modifications on the Retention of Cementretained Implant Crowns under Fatigue Loads: An In vitro Study. J Pharm Bioallied Sci. 2017 Nov;9(Suppl 1):S154-S160.Pubmed PMID: 29284956.

[18]. Ashok V, Nallaswamy D, Benazir Begum S, Nesappan T. Lip Bumper Prosthesis for an Acromegaly Patient: A Clinical Report. J Indian Prosthodont Soc. 2014 Dec;14(Suppl 1):279-82. Pubmed PMID: 26199531.

[19]. Venugopalan S, Ariga P, Aggarwal P, Viswanath A. Magnetically retained silicone facial prosthesis. Niger J Clin Pract. 2014 Mar;17(2):260-4. Pubmed PMID: 24553044.

[20]. Ashok V, Suvitha S. Awareness of all ceramic restoration in rural population. RJPT. 2016;9(10):1691-3. 
[21]. Basha FYS, Ganapathy D, Venugopalan S. Oral Hygiene Status among Pregnant Women. Research Journal of Pharmacy and Technology. 2018;11:3099.

[22]. Frush JP. Linear occlusion. Ill Dent J. 1966 Dec;35(12):788-94.Pubmed PMID: 10895639.

[23]. Gronas DG, Stout CJ. Lineal occlusion concepts for complete dentures. J Prosthet Dent. 1974 Aug;32(2):122-9.Pubmed PMID:4601726.

[24]. Kingery RH. A review of some of the problems associated with centric relation. J Prosthet Dent. 1952 May 1;2(3):307-19.

[25]. Trapozzano VR. Occlusal records.Journal of Prosthetic Dentistry. 1955; 9:325-32.

[26]. Porter CG. Simplicity versus complexity . Journal of Prosthetic Dentistry. 1952;2: 723-9.

[27]. McCord JF, Grant AA. Registration: stage II--intermaxillary relations. Br Dent J. 2000 Jun 10;188(11):601-6. Pubmed PMID: 10893814.

[28]. Fenlon MR, Sherriff M, Walter JD. Association between the accuracy of intermaxillary relations and complete denture usage. J Prosthet Dent. 1999 May;81(5):520-5.Pubmed PMID: 10220655.

[29]. Watanabe Y. Observation of horizontal mandibular positions in an edentulous patient using a digital gothic arch tracer: a clinical report. J Prosthet Dent. 2004 Jan;91(1):15-9. Pubmed PMID: 14739888.

[30]. Abe J, Kokubo K, Satō K. Mandibular Suction-effective Denture and BPS: A
Complete Guide. Quintessence Publishing (IL).2012: 291.

[31]. POSSELT, U. Studies in mobility of the human mandible. Acta Odontol Scand. 1952;10:1-160.

[32]. Boucher LJ. Limiting factors in posterior movements of mandibular condyles. J Prosthet Dent. 1961 Jan 1;11(1):23-5.

[33]. APRILE H, SAIZAR P. Gothic arch tracing and temporomandibular anatomy. J Am Dent Assoc. 1947 Aug 15;35(4):256-61.Pubmed PMID: 20255348.

\section{Special Issue on}

"Prosthodontics and Maxillofacial Prosthetics"

Theme Edited by:

Yi-Fang Huang, Associate Professor, Chang Gum Memorial Hospital, Taiwan.

E-mail: yifang0324@gmail.com 